\title{
KCI Technologies, Inc. - Engineering The Future, One Employee At A Time
}

Vera L. Street, Salisbury University, USA

Christy Weer, Salisbury University, USA

Frank Shipper, Salisbury University, USA

\begin{abstract}
To an outsider, KCI Technologies may appear to be a typical, run of the mill engineering firm. However, once introduced, prospective clients soon understand why KCI was recently ranked $83^{\text {rd }}$ on the Engineering News-Record's list of the top 500 engineering firms in the country, $7^{\text {th }}$ on its list of Top 20 Telecommunications Firms, and 55 ${ }^{\text {th }}$ out of the Top 100 'Pure' Designers. With a focus on providing the highest quality service through a commitment to innovation and employee development, KCI is clearly positioning itself for the future. KCI Technologies is currently the largest employee-owned, multi-disciplined engineering firm in Maryland. Providing consulting, engineering, and environmental construction management services, $\mathrm{KCI}$ had revenues of approximately \$131 million in 2009, and serves clients in the Northeast, Southeast and MidAtlantic regions of the US. The more than 900 employee owners of KCI operate out of offices in 12 states - Delaware, Florida, Georgia, Indiana, Maryland, New York, North Carolina, Ohio, Pennsylvania, Tennessee, Virginia and West Virginia, as well as the District of Columbia. KCI has undergone incredible changes over the last several decades. From a basement dream, to a multi-million dollar employee owned organization, KCI is poised to face the future. However, with an uncertain economy and reduced governmental and private-sector spending, will the loyalty and commitment of the employee-owners be enough for KCI to continue building the impressive set of awards and recognition for which the company has become accustomed?
\end{abstract}

Keywords: ESOP; Shared leadership; Intellectual capital; Organizational culture

\section{INTRODUCTION}

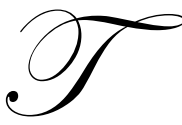

he company, now known as KCI was founded in Baltimore County, Maryland, in 1955 in the basement of one of its co-founders. In 1977, the company was purchased by industrial products conglomerate, Walter Kidde \& Company, and was subsequently merged with three other architectural and engineering firms into an engineering subsidiary that came to be known as Kidde Consultants Inc., or KCI. In 1987, Kidde was purchased by Hanson Trust PLC, a British manufacturing company with diversified holdings worldwide.

Although Hanson favored some of the Kidde businesses, there was a lack of fit between KCI and its new parent company. In particular, being a service-driven firm, as opposed to a product-oriented manufacturing company, KCI's measures of profitability were not consistent with Hanson's expectations. As an example, Terry Neimeyer, explained:

They had a term called, "Return on Capital Employed, "... and they expected any company that worked for them to have an ROCE of 80 percent.... We said, "Well, look, we are an engineering company, we're lucky to do 5 or 6 percent and we think we're doing well at 5 or 6 percent" and they said, "Look, our number's 80 percent."

Even beyond the inconsistencies with respect to financial expectations, the corporate cultures of Hanson and KCI differed drastically. KCI was used to having autonomy in decision making and authority. Hanson on the other hand, took a much more centralized, top-down approach to management. For example, as Neimeyer 
remembers, "if you wanted to buy a computer, you would have to go to London and make a presentation."

It was no secret that Hanson's business strategy was to enter the U.S., buy a conglomerate, keep what they viewed to be their profitable assets - assets that would be returning 80 percent - and then divest the unprofitable assets. Thus, aware that Hanson would likely want to sooner rather than later divest of KCI, senior managers had an idea. Driven largely by self-preservation, but also with a touch of optimism, the top management team thought, "Hey, let's see what we can do to buy ourselves." And why not? Who knew what would happen if KCI were to be taken over by another company? Indeed, there was a level of excitement over the potential of being a part of, and perhaps even leading, an employee owned company.

Unfortunately, Hanson was not at all receptive to the idea. As Neimeyer remembers, Hanson's view on selling KCI to its employees was:

Absolutely not. We do not sell to people. We do not sell to former employees. It's just not what we do. We'd like to sell and rid ourselves of this [company] and it's over... and we don't do it [sell to former employees].

However, by this time, the KCI senior management team was actively seeking a strategy to make a buy-out happen. Having determined that alone the senior managers could not come up with enough equity to leverage a deal, they sought the buy-in of the $800 \mathrm{KCI}$ employees. An existing Kidde profit sharing plan, which had accumulated some significant funds, laid the foundation for employee contributions. According to Neimeyer:

We said, let's look at doing this where we'll ask people [employees] if they'd like to do it. We'll put out perspectives; we'll do a whole pro forma, which we did. And then people [employees] would have the option of contributing whatever they wanted. They could contribute 0 percent, they could contribute 100 percent, they could contribute anywhere in between. So, [based on our calculations as to the value of the company at that time], we basically had the scenario where ballpark figures it was 80 percent employee owned, with 20 percent held by these managers.

However, Hanson refused the offer. They were just not interested in selling the company to former employees.

Disappointed, but ever cognizant of the potential harsh consequences of being purchased by another organization, senior management at KCI went back to the drawing board. They knew the risks of upping the offer, but they also had confidence in their organization and, perhaps even more importantly, in their employees. Ultimately, they presented an increased, leveraged offer Hanson could not refuse. Shortly thereafter, KCI initiated an employee buyout and became a majority employee-owned company on December 15, 1988. On January 1, 1990, KCI established a qualified retirement program for the stock of KCI Technologies, Inc., to be held in trust by an Employee Stock Ownership Plan (ESOP). The ESOP initially owned approximately 82\% of KCI stock, however, in June 1998, the company bought all of the management shares (non-ESOP shares) and became $100 \%$ employeeowned. Terry Neimeyer is the current Chief Executive Officer and Chairman of the Board of KCI; Nathan Beil is the President.

\section{OPERATIONS AND QUALITY MANAGEMENT}

Although most people know an engineer or have at least met one, many may not know exactly what engineers do. To help better understand the nature of KCI, Harvey Floyd, a Senior Vice President and Chief Client Services Officer, offered the following as an explanation of KCI's businesses to outsiders:

You know what architects do, you know what lawyers do, you know what doctors do, but you have no idea what engineers do... you know when you get up in the morning and you turn the lights on; How do you think that light comes on? It's from the generators that were built by engineers, the power plants, the transmission lines, everything built by, everything was designed by engineers. [To clarify] Not built, but designed by engineers. Then, you walked over and turned the water on, and out came water. Well, where do you think the water came from? From the reservoirs, the towers, the pumps, the pumping stations, all designed by engineers. You flush the toilet. Where do 
you think it all goes? Pipes, the treatments plants, all designed by engineers. You drove across a road to get here. Where do you think the road came from? The bridge you drove over... who designed the bridges?

In other words, $\mathrm{KCI}$ is in the business of designing and coordinating facility and infrastructure projects and improvements for both the public and private sectors. Much of their work, approximately $80 \%$, involves public sector work from various Departments of Transportation (e.g., MD DOT, Georgia DOT, PennDOT). Examples of work KCI may become involved with in the private sector include projects at research parks and universities for contractors and developers. Figure 1 provides examples of recent projects undertaken by KCI.

Figure 1: Example KCI Projects*

\begin{tabular}{|l|l|l|l|}
\hline \multicolumn{1}{|c|}{ Project } & \multicolumn{1}{|c|}{ Discipline } & \multicolumn{1}{c|}{ Location } & \multicolumn{1}{c|}{ Description } \\
\hline St. Mary's County Courthouse & Construction & Leonardtown, MD & $\begin{array}{l}\text { Construction management over } \\
\text { renovation and expansion of } \\
\text { historic courthouse. }\end{array}$ \\
\hline $\begin{array}{l}\text { Clarice Smith Stormwater } \\
\text { Management Pond }\end{array}$ & Environment & College Park, MD & $\begin{array}{l}\text { Designed changes to stormwater } \\
\text { management pond. }\end{array}$ \\
\hline $\begin{array}{l}\text { Capitol West Refrigeration Plant } \\
\text { Expansion }\end{array}$ & Land Development & Washington, DC & $\begin{array}{l}\text { Survey and layout services for } \\
\text { plant expansion. }\end{array}$ \\
\hline Gettysburg Interchange & Transportation & $\begin{array}{l}\text { Cumberland County, } \\
\text { PA }\end{array}$ & $\begin{array}{l}\text { Team lead for highway } \\
\text { interchange project. }\end{array}$ \\
\hline Bonita Springs Tower & Telecommunications & Bonita Springs, FL & $\begin{array}{l}\text { Worked on repair of tower } \\
\text { damaged by hurricane. }\end{array}$ \\
\hline Verizon & Telecommunications & Varies & $\begin{array}{l}\text { On-call to provide engineering } \\
\text { services to Verizon. }\end{array}$ \\
\hline Suwannee Pedestrian Bridge & Transportation & Suwanee, GA & $\begin{array}{l}\text { Engineering services for bridge } \\
\text { and Boardwalk. }\end{array}$ \\
\hline
\end{tabular}

*Adapted From KCI website

The competitive environment facing KCI, as well as the need for precision in the nature of the projects undertaken, drives a quality-focused culture at KCI. In part, there is the recognition that repeat business is critical, and to get that repeat business, projects must be completed to precision. When things do not go as well as expected, it is not uncommon for $\mathrm{KCI}$ employees to get out in the field to figure out what could be improved upon for future projects.

Quality is important on both the business side as well as the technical side of the work done at KCI. On the business side there are quality issues with, for example determining project scope, understanding and negotiating client needs, and understanding regulations. On the technical side, the quality of designs, calculations, and reports and plans must be regulated. Because there are no set products that are being produced, as every project is different, these are challenging tasks.

Obtaining and maintaining ISO certification has been an important quality initiative at KCI. However, obtaining this certification has not been without its challenges. To begin, the standard was initially developed for manufacturing firms. Thus, as a service firm, $\mathrm{KCI}$ has had to adopt very broad interpretations of various components of the standard. Additionally, as a requirement, KCI had to explicitly write down their business processes. This proved to be somewhat of a hurdle, because, as Floyd put it, “. . . a lot of these things are "that's just the way we do it"." Another issue was getting people to exert the extra effort required to obtain the certification. Senior management tried to make this as painless as possible, and they were quick to point out that, although some extra effort was necessary, often times this effort resulted in not only a step toward certification, but also in making business processes easier than they were before.

Logically, they began slowly, just focusing on part of the company. Then as the benefits were seen, it was decided to begin certification for the whole company in order to take the quality of their processes to the next level. The requisite codification of best business and quality control practices has helped to impose a level of discipline in the company's processes that may not have been present prior to the certification. And, although it is not necessarily 
required by all clients, it is looked upon very favorably and helps to win business. At this time, not all of KCI businesses have been certified however, they are actively seeking how to do so.

\section{MARKETING}

Given that $\mathrm{KCI}$ is an engineering services firm, marketing is different than in a traditional manufacturing company and is even different from many other types of service firms. Marketing is primarily done through the preparation of proposals and statements of qualification for potential clients. Ultimately, work is secured because of the "expertise and experience of the technical staff at KCI." According to Deborah Boyd, Director of Proposal Preparation:

I would say that 90 percent of our marketing falls within developing project descriptions of work that we've done in the past, employee resumes. Our marketing is very technical in nature, where it revolves around the projects and the staff team qualifications and the qualifications of our sub-consultants.

The process begins by finding potential clients who have jobs that need to be done. This primarily happens in two ways. The first, more conventional route is done by searching for client advertisements. This is usually done by the marketing staff searching online and/or looking in trade publications. A second, perhaps more fruitful route is done by a type of networking. Here, the Business Development staff, as well as other employees working on various projects, keeps in contact with current and past clients to see what other projects they have in the pipeline. Other consultants that KCI has worked with also often prove to be a good source of leads. The marketing staff track these potential projects. Then, a qualified technical lead is brought in to work on the proposal that will be drawn up for the potential client.

The business development staff meets with the potential clients to ascertain information that will help in the proposal writing process. They try to determine what exactly the potential client is looking for, e.g. a probable price range, or any "hot buttons." Whereas general advertisements by these clients can be fairly generic and don't always contain everything the client is looking for, the Business Developers play a critical role in information gathering. The marketing staff then pulls together this information, matches it with the qualifications of KCI and prepares a package to submit to the potential client.

put it:

A key to this process is to get shortlisted. This is an area in which KCI may be able to improve. As Boyd

So either we're not qualified to do the job or we're qualified and we didn't show it very well. And if we're qualified and we didn't show it very well, that's a reflection on me because that means my proposal didn't answer the questions in the RFP.

An important part of the marketing effort is building project descriptions on prior work and maintaining a database of these descriptions. The project descriptions are like a project "resume." They contain information about the project, including the qualifications of the team that worked on it, and qualifications of any sub-consultants.

Additionally, there are efforts aimed at increasing potential clients' awareness of KCI. One way that KCI attempts to build awareness is by standardizing their proposals. Consistency in fonts and colors is maintained so that potential clients can recognize a KCI proposal at a glance. Another example of how KCI attempts to increase awareness is through their corporate website. The website is continually updated to highlight successful projects they are currently working on or have completed. Other corporate communications are also available to interested parties. They produce folders of information including descriptions of successful projects they have completed, indications of awards they've won, and lists of where they are operating. Additionally, presentations at conferences and seminars help to promote the employees of KCI as experts in their respective fields.

\section{HR AND INTELLECTUAL CAPITAL DEVELOPMENT}

Clearly, in such a technically focused, service oriented organization, employee knowledge and expertise are 
key elements for success, and this is not taken for granted at KCI. There are many ways in which intellectual capital is developed, starting right from the beginning; every attempt is made to hire the right people!

With a focus on shared leadership, hiring managers have a hand in developing realistic job descriptions. Openings are first posted internally, allowing current employees the opportunity to investigate and pursue available positions. After five days, the openings are posted externally. Often, department managers are involved in the entire hiring process, from creating job descriptions to pre-screening applicants, to interviewing and making final hiring decisions. Although talent is hard to come by, Tammy Jones, a Vice President and HR Director, feels that KCI gets high quality applicants due to the company's reputation for doing great work in high profile projects projects of which employees are proud to be a part.

Once hired, employees have the option to become involved in a year-long formal mentoring program at KCI. This program, launched about three years ago, was established, in large part, in an attempt to keep the intellectual capital developed at KCI from moving to competitor firms. New hires are paired with more senior employees and move through a 12-month formal mentoring regime. Most senior managers mentor two or three new hires each year and the program appears to be paying off. As indicated by Jones:

When I came to KCI, which was almost five years ago, previous employee surveys, as well as our turnover reports, indicated that we were losing employees at two to three years; thus launched the formal mentoring program. Actually, I was reviewing those statistics recently and we're retaining about 33 percent more than we did prior [to the mentoring program].

Beyond the mentoring program, formal training and development programs are a cornerstone of intellectual capital development at KCI. Perhaps most notably is an extensive set of leadership development programs for which employees at various levels of the organization can be nominated. The series includes three programs: Emerging Leaders, Professional Leaders, and The Advanced Leadership Program.

The Emerging Leaders Program typically consists of 40-60 individuals who have been with the company for fewer than five years. Designed by an outside consultant, employees are nominated and accepted into the Emerging Leaders program based on their leadership potential as noted by their immediate manager. Participants meet every other month for 24 months and have a culminating project focusing on the development of a KCI initiative. According to Beil:

On the Emerging Leaders, for example, you have the team building piece as well as training on interpersonal skills, basic management, priority management, conflict management or resolution, stress management, positive reinforcement, and motivation. Sometimes it's hard to motivate even yourself, so expressing yourself in the proper way. And, we actually have a graduation program for these folks...

The Professional Leaders program is more selective and is typically limited to 20 employees. This program was also designed with the help of an outside consultant and is continuously customized based on survey feedback from KCI middle managers. The program runs for one year - in Spring and Fall "semesters" - and focuses on topics such as motivating others, coaching and developing others, and relationship management. Participants complete a number of self-assessments, which allow them to better understand themselves and their roles within the organization. With a variety of "credits" to choose from, the program culminates in a three-day off site Foundations of Leadership Program offered by the University of Maryland.

The third and final component, the Advanced Leadership Program is facilitated by an outside consultant. This intimate, high-level, high-touch component is composed of only those nominated employees who are deemed as potential Vice Presidents of KCI. The Advanced Leadership component is an intense development program consisting of deep level soft skills training. This program has not been offered at KCI in a while.

Another development program is the Project Management Academy. This is a one day, annual event during which participants become deeply involved in project and quality management issues. There are three levels for the program, all focused on project scope, scheduling, and budgeting, but at the highest level the soft skills of 
management are also honed. Participants in this program are typically those at the project management level or above.

Other types of development are available or supported as well. For instance, there is support for CAD training, safety training, LEED certification, and various software training. KCI hires and supports interns. Additionally, there is a licensure management system to help everyone stay on top of their licenses. Educational assistance is also available at $100 \%$ cost reimbursement after an employee has been with the company for five years; $80 \%$ if they've been with KCI for fewer than five years. And all of this is not to mention the informal training that occurs at KCI on a daily basis. As one can imagine, KCI earmarks significant resources for these training and development programs. Senior management at KCI feels that these career-development initiatives are a necessity to recruit and retain the high-quality talent for which $\mathrm{KCI}$ is known.

\section{FINANCE}

Given the recent economic downturn, most firms have been faced with financial difficulties. KCI is no exception. This is exhibited by a considerable drop in revenue in recent years. In 2007, total revenues were $\$ 142$ million, in 2008 revenues stayed constant at \$142 million; however, in 2009, revenues dropped to $\$ 131$ million. Despite this decline, Neimeyer is optimistic, "dealing with this economy - this is my fourth recession, you know this will pass. I know that it will."

Neimeyer has reason to be optimistic. According to a recent Business Week article, one way to help a company overcome an economic downturn is to practice open book management. And, KCI does just this. The financials for the company are open. Employees can ask to see most anything regarding the financial health of the organization. This is important to employees as a portion of their compensation is based on the financial well-being of the company. KCI makes an ESOP contribution based on a percentage of an employee's salary, currently $6.5 \%$, which vests in five years. Despite its ups and downs, the ESOP share price is impressive. At inception, one share was worth $\$ 1,000$; now it is valued at almost ten times that amount (Figure 2).

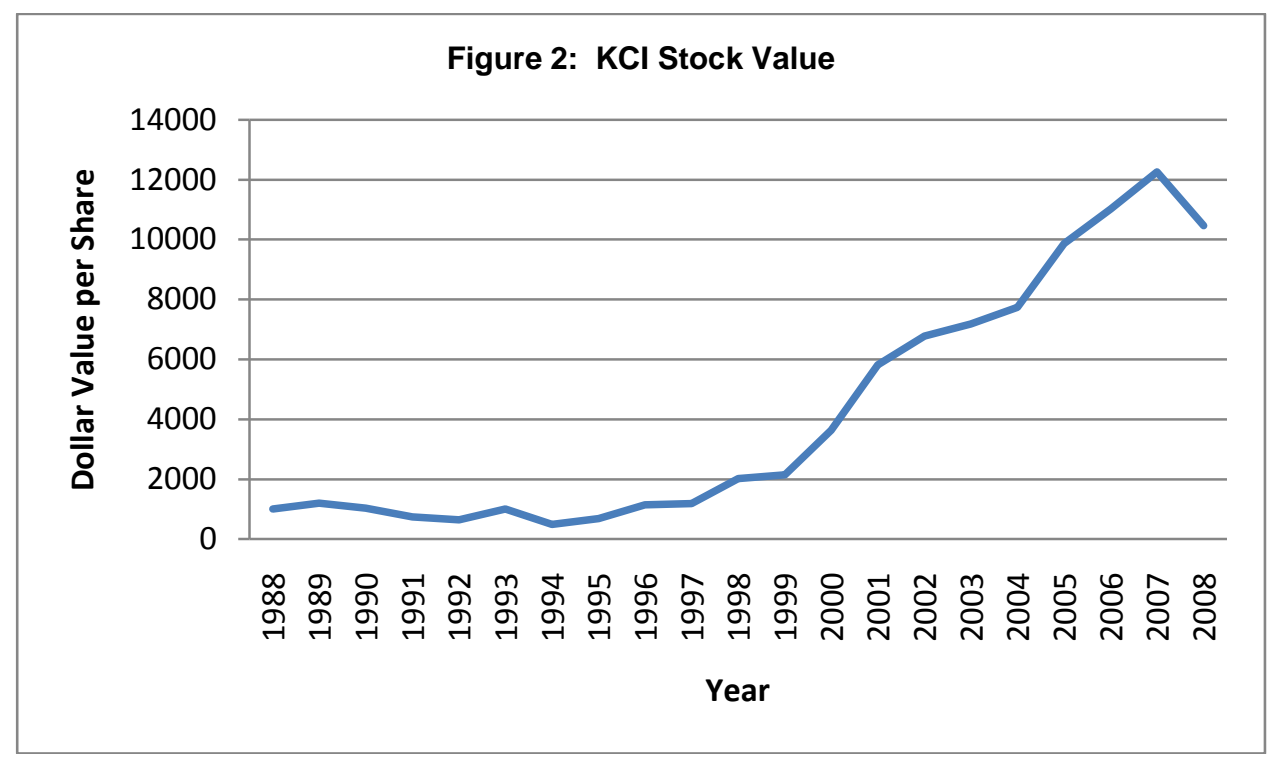

As one employee commented:

It was amazing to see, over the years, how much the ESOP continued to make money over time. One of my coworkers, who has been here 12 years now, has thousands of dollars in this ESOP that he's never had to put any money aside. 
To get continued employee buy-in, ESOP education is constant. The company has several events during the year that promote awareness about the program, such as a contest where employees guess the exact value of the stock. Interestingly, and a good sign, many employees' guesses are not too far from the true value. ESOP bingo is another exciting event where employees - even those out in the field -have a chance to play and learn ESOP definitions and terminology.

Sharing in the ESOP is truly that - equal sharing. The largest stock holder is only so because he has been with the company for the longest length of time. No one receives extra perks to make their percentage of stock ownership particularly high, and unlike cash flow issues that can sometime arise when employees leave an employee-owned company, KCI has not had issue with cashing people out. So they know the money from the ESOP is real and truly is the employees'.

Since in service organizations employee compensation is typically such a huge part of the financial outlay, it is worth noting other forms of compensation here. Aside from the ESOP and regular wages or salaries, top earners at KCI have an "at risk" compensation incentive. A portion, typically 5-30\% of their compensation is based on the profitability of the business for which they are involved. Additionally, the top 20 earners have a deferred compensation plan. This plan is designed to make the compensation of top employees a bit more competitive with that at rival partnership firms.

$\mathrm{KCI}$ also offers generous benefits to its employees. These vary from a $401 \mathrm{~K}$ with a company match, to a floating holiday. One benefit that employees find particularly beneficial is tuition assistance. As previously mentioned, KCI pays $100 \%$ after an individual has been with the company for more than five years. Many employees feel that it is an excellent program. As one employee who recently completed a graduate program put it,

Excellent, excellent program. I mean, I wouldn't have been able to pay for it had it not been for KCI. So to me, that's another huge benefit. If feel like I owe them [KCI] something because of the benefit. I mean, it's huge.

Tuition assistance also enriches the firm by increasing KCI's intellectual capital and qualifications needed to successfully bid on additional projects.

\section{THE COMPETITIVE MARKETPLACE}

Considering such a large portion of KCI's projects are public sector projects, it is important to consider this marketplace. There are opposing forces at work here. On one hand, the aging infrastructure in the US could create great demand for the services of firms like KCI. On the other hand, there are potentially severe budget constraints that could limit the number and profitability of projects requiring those services.

That being said, KCI faces fierce competition. Because they are a multi-disciplined (e.g., construction, environmental, transportation) engineering firm, the competitors that they meet for a given project depend upon the business line(s) needed for that project. Some of their competitors are regional, employee-owned firms of about the same size, like JMT. Others are large, international publically traded firms like Michael Baker Corporation. Additionally, there are many partnerships in the mix, like RK\&K, LLP. But, it's important to note that in this field, the competition is not always the competition. Often times firms will be competing with each other for one project and be partners on another. That is, when there is considerable overlap in the skills between two firms, they may compete with one another for a project. However, sometimes the firms will have complementary skills needed to best meet the demands of a potential client, so they will partner with one another.

Two keys to successful competition in this arena are having the proper qualifications for a potential client's project and having relationships built with clients and partners. A company must have the talent available to meet the needs of a potential client's project. This means having available employees with the proper education, experience, and certifications. But just having this talent is not quite enough. As previously mentioned, the company must be able to expertly demonstrate the fit between the company's expertise and the client's needs. Proper coordination of talent and being able to show the fit to the project can be challenging. 
Having strong relationships with potential clients and partners is critical to get a leg up on the competition. These relationships are used to both learn about new projects and to find out more detail about potential projects. The earlier a company can start working on a proposal for a potential project and the more specific the proposal is, the more likely they are to beat the competition.

An additional significant area of competition is the competition not for clients, but rather for employees. In the US, the engineering population is "graying." That is, there is a great shortage of new talent, so firms have to fight over the talent that's out there. According to Beil, KCI relies on their challenging work environment and open culture to capture great talent. Beil also mentioned that they had hoped that the ESOP would be a great recruitment tool, but this has not turned out to be the case. Today's applicant pool is really looking for a job for a couple of years, rather than a career with an organization. As such, they would not be as likely to see the benefits of the ESOP. But that is not to say it is without its recruitment merits. When one employee was asked what brought her to KCI, she commented, "The things I really liked about KCI, besides the staff - we have a great staff here. They had a really good benefits package. The ESOP was very appealing to me. .."

At the upper management level, a different scenario plays out. Many of KCI's competitors are partnerships, and partnerships allow the partners to have a higher earning potential than that expected of the top executives in an ESOP. As such, it could be difficult to recruit into these positions. But, at least recently, according to Beil, finding upper managers has not been an issue. He believes this due in part to the nature of financial risk differences in the two types of organizations. The financial risk facing the upper managers in an ESOP firm tends to be less than that which faces partners in a partnership.

\section{SHARED LEADERSHIP}

Leadership is about integrity and credibility. Accordingly, Beil feels that letting people know where things stand is important, and never promising more than you feel you can deliver gets real buy in. It's not at all about 'just barking orders to employees." The KCI leaders see their role as articulating a vision that resonates with employees.

This mentality is largely derived from the culture at $\mathrm{KCI}$, but it is also a result of being employee owned. Employee involvement resonates through the organization and it is clear that the employees play a large role in the overall direction of the organization. For instance, an employee designee serves on the board of directors. According to Beil:

So our employees actually have a popular election where they elect a member to the Board of Directors...They go out and they have to get ballots and they have to get 35 shareholders sign [the ballot] to say the employee is "OK". And then there's this popular election...

Now the true power in any ESOP organization is in its trustees, as trustees control the voting of the stock on all things with the exception of mergers and acquisitions and major changes to corporate bylaws. Interestingly, two non-management employee members are also on the Board of Trustees at KCI - one elected employee member and one appointed. Having an employee representative involved in governing and approving major decisions for the organization is a true example of shared leadership.

In addition to having formal representation on the Board of Directors and the Board of Trustees, it is clear that there are many avenues for open communication that allow ideas to filter from the lower ranks of the organization to the upper echelons. Niemeyer commented:

One thing about it, and it may be our management style, is that our people have a tendency to speak up. And when they do speak up, they speak up without fear of repercussion. So it's not as if they're worried about saying something in a meeting or to me or to the president and all of a sudden seeing the Grim Reaper come and fire them.

Others in the organization have echoed the idea that there is open and easy communication up the organizational ladder. Indeed, the leaders at KCI provide many avenues through which employees can bring up issues, comment on processes, and make other suggestions to management. As an example, The Companywide 
Employee Committee (CEC) was formed whereby 36 members, representing each department, meet on a regular basis to discuss issues that are raised from members of their respective departments. In essence, this committee, for which membership rotates on a yearly basis, acts as a sounding board for employee concerns.

In addition, anonymous survey boxes are located in the cafeteria, and an annual survey provides an outlet for employees to provide feedback on a wide range of topics including job satisfaction, human resource issues, compensation, supervisors and coworkers.. Moreover, a blog, to which employees may anonymously post, will soon be available as another mechanism for employee feedback. Town hall meetings, though in practice are primarily a top-down information dissemination tool, provide an additional venue where employees could voice their ideas. Moreover, senior management pride themselves on their availability and openness through an open-door policy.

It is not unusual to hear that organizations are "employee friendly" or have "open door communication"; however, sometimes these espoused views are simply not enacted. However, at KCI, what they preach is exactly what they practice. Employee suggestions do not go unheeded. One key example is the creation of one of KCI's business lines, the Geographic Information Systems (GIS) group. According to Neimeyer:

The GIS group idea really came up through the organization by some computer folks who weren't in the engineering field, but said, "Look, I think there is going be a business line in geographic information systems. And it's something that we can really deal with the engineering or the planning sector even though it's not typical engineering." And, so one gent came and said, "Hey look, let me take this on. I think I can create a business on this and make a business line." And, that's an example of an idea that came up [through the ranks] and spawned a business.

Another initiative generated from the employees is a technology refresh program, where technology updating is based on technological advancements rather than on a fixed time interval. Neimeyer jokes, "It's not like I come up with all these ideas. I've been here 32 years. My new ideas are limited." These examples make apparent the notion that employee ideas get heard and implemented.

The idea of open lines of communication and continuous implementation of employee ideas is not only an upper echelon perception. Employees do indeed feel like their ideas are respected and welcomed. As one employee put it, "the culture is one where everyone, from the leaders at the top to the newest non-management employees, is in it together."

\section{INFORMATION SHARING}

Communication of information is critical in any organization, however, in an ESOP, employees have more of a vested interest in understanding, retaining, and utilizing information disseminated to them. Neimeyer and Beil have similar views:

...on the ESOP side [as compared to a partnership], communication skills probably have to be a step up. I think your ability to have a vision, and articulate it, then lead the company through it, has to be a step up.

Employees' echo this sentiment. For instance, an employee offered:

I've worked for a partnership before. I had no idea how I was doing on a project, how much money we were making, how much money the company was making, whether my project was a success or not because the profits all went to the partners. In an ESOP culture, we're all owners. We all know what's going on, and because of that, we push information down to our employees.

Another employee added:

We try really hard to communicate what's going on. We have town meetings once a month. The managers are very open to talking to employees. I mean, they'll tell you, "I can't tell you; it's not for discussion right now," and they're honest. 
KCI has formal approaches to getting important and worthwhile information out to employees. As mentioned above, town hall meetings play an important role in information sharing. These open meetings are held by the President once per month at headquarters with those in remote locations tele-, video-, or web-conferencing in. The meetings are also recorded and shared on the company intranet. During these meetings the status of the company is shared, company-wide issues are addressed, like changes to benefits or austerity measures, and exciting new projects are announced. Financial results are also shared quarterly.

In addition to town hall meetings, departmental managers hold monthly meetings with the hope that the information shared will be funneled down through the company ranks. To help facilitate this process, minutes from the meetings are sent out to second tier management.

Beyond these formal approaches, more informal channels of communication exist as well. Even the CEO takes a hands-on approach to information sharing. For example, he attempts to reach out and visit branch offices. On his visit he says his approach is to, "just sit with the people and you ask them how things are going and have a little staff meeting and tell them what's going on." Regarding information sharing in general, he comments:

And again, we try and continue to do it. It's a never ending cycle. You can never do enough of it. And in our company we get critiqued for not doing enough of it. No matter what we do, we still have to do more.

\section{GROWTH AND CHANGE THROUGH INNOVATION AND INITIATIVES}

It is well understood that KCI cannot simply rest on its laurels and continue to do business as it has always done. Innovation is key to continued growth and development and KCI has been involved in some innovation, forward thinking projects. For instance, Floyd recalls one innovation done to mitigate the impact of a bridge on the environment:

There were just a number of things that were blocking fish passages, so the fish couldn't go back up the river to spawn, they hadn't for years. So as part of the mitigation effort, the State Highway Administration agreed to create these natural fish passages. They didn't want fish ladders. They didn't want pipes. They wanted natural. Well, this is something that we haven't necessarily done on the East coast, but they're doing it in the West. So some of our guys went out to the West and studied what was being done out there by literature searches, talking with people, and going out visiting.

We saw what they were doing, but what they were doing they were doing in a rural area. We had to do this in an urban area, so our environmental scientists and our hydrologic people actually developed the design method to take that technology and apply it in an urban environment. What they did was they built these natural fish passages in the bottom of the streams, so depending on what type of fish you had, it would determine how strong the fish - what current the fish could swim up, how strong the current could be, and how long they could (swim against) it, their endurance. So what they had to do was they had to design these rock ladders, basically, these fish ladders so that the fish could make it up through the current, and then they had to space boulders to form these little resting areas for the fish so they could get up the stream. . you would never know that it was a manmade thing. It just looks like it's natural, but in actuality, they were purposely built and constructed so the fish could get up over the natural blockages. We won a lot of awards for that because that was very innovative.

Providing environmental-friendly solutions to client problems comes natural to KCI, perhaps because the company and its employee owners are invested in sustainability themselves. KCI's headquarters, one of Maryland's newest green buildings, has recently been awarded the US Green Building Council's (USGBC) Leadership in Energy and Environmental Design (LEED) gold certification. The 120,000 square foot building features a white solar reflective roof, which reflects sunlight in the summertime reducing the air-conditioning requirements, a stormwater management pond, and high-performance climate control plumbing and electrical systems, all designed by KCI engineers and LEED specialists. According to Neimeyer, the facility uses resources more efficiently than traditional office buildings and offers employees a healthier and more comfortable work environment. 
Indeed, KCI has a forward-thinking mindset. Not being afraid to take on new initiative is another hallmark of KCI's continued growth. In a typical year, $15-20 \%$ of profits are used to fund new corporate initiatives - those that are funded at the corporate level because they tend to be too expensive for an individual division. Usually, an initiative runs upward of $\$ 250,000$. A prime example is the aforementioned GIS division. This began as a corporate initiative and was funded as such until it reached a critical mass of clients. It now operates on its own with 22 employees. This is not to say that all initiatives work. If an initiative is not on target at year three, funding will be reallocated to other projects, and the initiative will be discontinued. But, one cannot expect rewards without taking some risks.

\section{THE REORGANIZATION}

KCI is in the process of reorganizing. This is a step they have been considering since the mid 1990's. For the most part, KCI has taken a geographic approach to their structure. Now, they are moving to a discipline-based approach. This includes such disciplines as transportation facilities, site management, telecom, and urban planning and development surveys. The headquarters has been somewhat organized by discipline, but the remainder of company has not. The geographic regions were initially established to help promote geographic expansion, and to aid in succession planning at KCI. Unfortunately, particularly during downtimes in the economy, regions would be very protective of their resources and be out for themselves - not for the good of the whole company. It is expected that the new discipline based approach will be more integrated and less territorial.

The President has vested a great deal of time and effort into trying to facilitate a smooth transition. He has discussed the expectations for the reorganization with individuals, small groups, and large groups. Employee survey data indicate that employees are generally favorably disposed toward the reorganization; however there are employees who feel that they aren't really affected and that it's mostly a management reorganization. Some believe that people will not quite understand what is happening and why until the official reorganization has taken place and until results start coming in. Additionally, there is some sentiment that the reorganization will be quite challenging because, although senior management realizes that role definition will be important, the lines of authority in the organization may not be as clear after the reorganization. It is expected that there will be more shared and collaborative leadership.

\section{LOOKING FORWARD}

With the current economic uncertainty, KCI faces an all too common challenge among businesses securing enough business to keep their highly talented and committed employees working. According to Beil:

We don't hire for a job and then we fire them later. That's really not our efforts....right now, we're just maintaining it [the firm], finding enough work so that we don't have to tell a good person to find work elsewhere is probably what keeps me awake at night the most.

This is not to say that KCI is not constantly looking for good talent. When asked about the future of the organization, Beil, was quick to mention:

Our challenge will always be finding highly competent people. We're laying people off in a certain sector, but there are other sectors that are strong where we're looking to hire people. And finding talented people is a marathon struggle for us.

\section{ACKNOWLEDGEMENT}

The authors would like to thank the employee-owners of KCI Technologies who graciously shared their knowledge, experiences, and perspectives about the company. Their viewpoints were invaluable in ensuring that this case provides a true representation of the culture and practices of the company. In addition, the authors would like to thank the Beyster Institute and the Foundation for Enterprise Development for their support of this work. 


\section{AUTHOR INFORMATION}

Vera L. Street (Ph.D. Florida State University) is an Assistant Professor of Management in the Franklin P. Perdue School of Business at Salisbury University. Her research interests include competitive dynamics and employee ownership .Her articles have appeared in the Journal of Management, Academy of Management Executive, Journal of Business Venturing, Journal of Business Ethics and others. Additionally, with Marc D. Street, she co-authored the $2^{\text {nd }}$ and $3^{\text {rd }}$ editions of Taking Sides: Clashing Views in Management.

Christy H. Weer (Ph.D. Drexel University) is an Assistant Professor of Management in the Franklin P. Perdue School of Business at Salisbury University. Her research interests include issues related to the work-family interface, career development, gender and diversity in organizations, and employee ownership. Her articles have appeared in the Journal of Vocational Behavior, Group and Organization Management, Journal of Applied Social Psychology, and others.

Frank Shipper (Ph.D. Utah) is Professor of Management and Chair of Management and Marketing in the Franklin P. Perdue School of Business at Salisbury University. His current teaching, consulting, and research interests are managerial/leadership skills development, and employee ownership and culture. His articles have appeared in the Academy of Management Journal, Organizational Dynamics, Leadership Quarterly, Human Relations, Academy of Management Learning \& Education, and others. He has been recognized by the Academy of Management and the Center for Creative Leadership for his work on management development. As a consultant, he assists organizations in developing and validating their management development processes.

\section{REFERENCES}

1. http://www.businessweek.com/smallbiz/content/jul2009/sb2009077_940499.htm

2. http://www.kci.com/ 